\title{
Vitamin D status, bone metabolism and bone mass in patients with alcoholic liver cirrhosis
}

\author{
Savic Z1, Damjanov D ${ }^{1}$, Curic N ${ }^{2}$, Kovacev-Zavisic B ${ }^{3}$, Hadnadjev L ${ }^{1}$, Novakovic-Paro J ${ }^{3}$, Nikolic $\mathrm{S}^{2}$ \\ Clinic for Gastroenterology and Hepatology, Clinical Centre of Vojvodina, Novi Sad, Serbia. zsavic021@gmail.com
}

\begin{abstract}
Introduction: Osteoporosis is seen in some 12-50 \% patients with liver cirrhosis. Detrimental effects of alcohol are exerted directly on the bone cells and indirectly on hormones. Vitamin $D$ is involved in osteoblast differentiation, bone matrix synthesis and bone mineralization, as well as in its decomposition. Vitamin $D$ deficiency has been reported in about 2/3 patients with liver cirrhosis.

Objective: Determination of vitamin D status, bone metabolic activity and bone mass in patients with alcoholic liver cirrhosis (ALC).

Methods: Thirty male patients with ALC were investigated in the period October 2011- March 2012. Total vitamin $\mathrm{D}$, parathormone, osteocalcin and CrossLaps were determined by the ECLIA method (electrochemiluminiscence immunoassay) using Elecsys 2010 analyzer. Bone mineral density was measured by means of dual-energy $x$-ray absorptiometry (DXA) using the Lunar Prodigy. Result analysis was performed using descriptive statistics and hypothesis testing, as well as nonparametric one-way analysis of variance, Kruskal-Wallis test, Mann-Whitney U-test, Pearson correlation coefficient.

Results: Deficiency in vitamin D $(<50 \mathrm{nmol} / \mathrm{l})$ was noted in $66.66 \%$ patients, with highest prevalence in ChildPugh $\mathrm{C}$ class patients (chi-square $=5.878, \mathrm{p}<0.05$ ). Osteocalcin levels were below the lower limit of normal in $86.7 \%$ patients. CrossLaps was increased in only $20 \%$ patients, but a significant increase was noted in Child-Pugh C class patients. Osteoporosis was diagnosed in $20 \%$ of patients, with no correlation with disease severity and vitamin D status.

Conclusions: Vitamin D deficiency is present in patients with ALC. Decrease in bone formation and bone mass is most probably multicausal (Tab. 2, Fig. 1, Ref. 30). Text in PDF www.elis.sk.

Key words: alcoholic liver cirrhosis, vitamin D, bone metabolism, bone mass.
\end{abstract}

Hepatic osteodystrophy includes metabolic bone diseases associated with chronic liver disease. Osteoporosis is usually dominant in patients with underlying chronic liver disease, occurring in some $12-50 \%$ of patients with liver cirrhosis $(1,2)$.

Osteoporosis results from an imbalance between bone formation and bone resorption causing reduction in bone mass (3-5). Assessment of bone metabolic activity is performed by laboratory analysis of blood and urine and by evaluating the markers for bone formation and resorption $(6,7)$.

Reduction in bone mass in patients with liver disease is determined by the aetiology, duration and severity of the disease as well as by numerous factors such as age, sex, genetic and immunological factors, dietary deficit and malnutrition, insufficient movement, hypogonadism, administration of corticosteroids and antiviral therapy, low calcium and vitamin D intake, impaired vitamin D metabolism in the liver, accumulation of iron and copper

${ }^{1}$ Clinic for Gastroenterology and Hepatology, Clinical Centre of Vojvodina, Novi Sad, Serbia, ${ }^{2}$ Center for Laboratory Medicine, Clinical Centre of Vojvodina, Novi Sad, Serbia, and ${ }^{3}$ Clinic for Endocrinology, Diabetes and Metabolic Diseases, Clinical Centre of Vojvodina, Novi Sad, Serbia

Address for correspondence: Z. Savic, Clinic for Gastroenterology and Hepatology, Clinical Centre of Vojvodina, Hajduk Veljkova 1-9, 21000 Novi Sad, Serbia.

Phone: +381.21 .4843808$ in the liver, cholestasis, loss of liver synthetic function etc. (8). The most abundant research was performed in the field of chronic cholestatic liver diseases and conditions pre and post liver transplantation, whereas viral hepatitis, haemochromatosis and alcohol liver disease were addressed more rarely.

Osteoporosis is diagnosed in 17-23\% patients with alcoholic liver disease. Alcohol directly affects bone cells, whereas the normal hormone balance and hormones that regulate mineral status, and foremostly the vitamin D are affected indirectly (9-11).

Vitamin D deficiency is reported in 2/3 of patients with liver cirrhosis, in 90-96\% patients waiting for a liver transplant and in $91-92 \%$ patients with chronic non-cholestatic liver disease (12-16).

The spectrum of vitamin D actions includes genomic effects via vitamin $\mathrm{D}$ receptor (VDR) present in the cytoplasm, i.e. cell nucleus, and non-genomic effects via the membrane receptors and second messengers. Vitamin D carries out the vital biological functions affecting numerous health aspects (17-21).

Vitamin D interacts with vitamin D receptor (VDR) in osteoblasts regulating the gene expression which positively affects their differentiation, bone matrix formation and bone mineralization. Vitamin D supports RANKL (receptor activator of NF kappa beta ligand)-mediated osteoclastogenesis, and stimulates RANK (receptor activator of NF kappa beta) and osteoprotegerin (OPG) 
production. Produced multinuclear osteoclasts dissolve bone mineral substance and bone matrix $(18,19,22)$.

Osteoblast dysfunction may play an important role in the pathogenesis of metabolic bone diseases associated with chronic liver disease, which can partly be attributed to disorders of vitamin D metabolism $(19,23)$.

The objective of this research was to investigate vitamin D status, bone metabolic activity and bone mass in patients with alcoholic liver cirrhosis (ALC).

\section{Methods}

The research encompassed 30 male patients with alcoholic liver cirrhosis, who were treated at the Clinic for Gastroenterology and Hepatology in Novi Sad or in outpatient facilities in the period October 2011 - March 2012. The severity of the disease was graded according to the Child-Pugh classification (24).

Quantification of vitamin D (total) was performed by ECLIA method (electrochemiluminiscence immunoassay) on automated analyzer Elecsys 2010, using the commercial kits manufactured by COBAS-Roche Diagnostics.

Vitamin D status is defined as its serum concentration described as adequacy $(>80 \mathrm{nmol} / \mathrm{l})$ and inadequacy $(<80 \mathrm{nmo} / \mathrm{l})$. Different degrees of vitamin D inadequacy are classified as follows: insufficiency $(50-79 \mathrm{nmol} / \mathrm{l})$, deficiency $(<50 \mathrm{nmol} / \mathrm{l})$, mild deficiency $(25-50 \mathrm{nmol} / \mathrm{l})$, moderate deficiency $(12.5-24 \mathrm{nmol} / \mathrm{l})$, severe deficiency $(<12.5 \mathrm{nmol} / \mathrm{l})(13,16)$.

Quantification of parathormone (PTH), osteocalcin - bone synthesis marker and CrossLaps (Cross-linking telopeptide of type 1 collagen) -bone resorption marker, was performed by the same method.
The analyzer Architect c8000 (manufacturer: Abbott) and original reagents from the same manufacturer were used for determining serum concentrations of alkaline phosphatase (ALP), total bilirubin, aspartate aminotransferase (AST), alanine aminotransferase (ALT), gamma-glutamyl transpeptidase (GGT), urea and creatinine, albumin, total proteins, calcium $(\mathrm{Ca})$, magnesium $(\mathrm{Mg})$, phosphorus $(\mathrm{P})$, potassium $(\mathrm{K})$, sodium $(\mathrm{Na})$, chlorine $(\mathrm{Cl})$, and glycaemia.

Ionized calcium concentration was quantified using iLyte analyzer by the indirect method of ion-selective electrode.

The 24-hour urinary calcium excretion was not done because of secondary hyperaldosteronismus in these patients, and due to the use of furosemid medications in some cases.

Quantification of sex hormones was performed via the immunometric assay, i.e. chemiluminescent microparticle immunoassay (CMIA), whereas IGF-1 concentration was determined by an enzyme immunoassay (EIA).

Prothrombin time (PT) was measured on an automated coagulometer ACL9000 (manufacturer: Instrumentation laboratory) using original reagent kit from the same manufacturer. The INR (International Normalised Ratio) corresponds with the obtained ratio $(\mathrm{R})$ of $\mathrm{PT}$, while considering an International Sensitivity In$\operatorname{dex}=1$ assigned to ACL9000.

Bone mineral density (BMD) was assessed by the method of dual X-ray absorptiometry (DXA) using Lunar Prodigy bone densitometer. Results were interpreted in $\mathrm{g} / \mathrm{cm}^{2}$. In patients under the age of 50, osteoporosis was defined also on the basis of Z-score $(\leq 2 \mathrm{SD})$, and in patients older then 50 according to T-score $(\leq$ $2.5 \mathrm{SD})(2,4,5)$.

The research was approved by the Ethics Committee of the Institution, Decision No 00-01/559, and the written informed

Tab. 1. Clinical features, bone metabolism and bone mass parameters in patients with ALC (whole group and categorization of patients according to Child-Pugh classification).

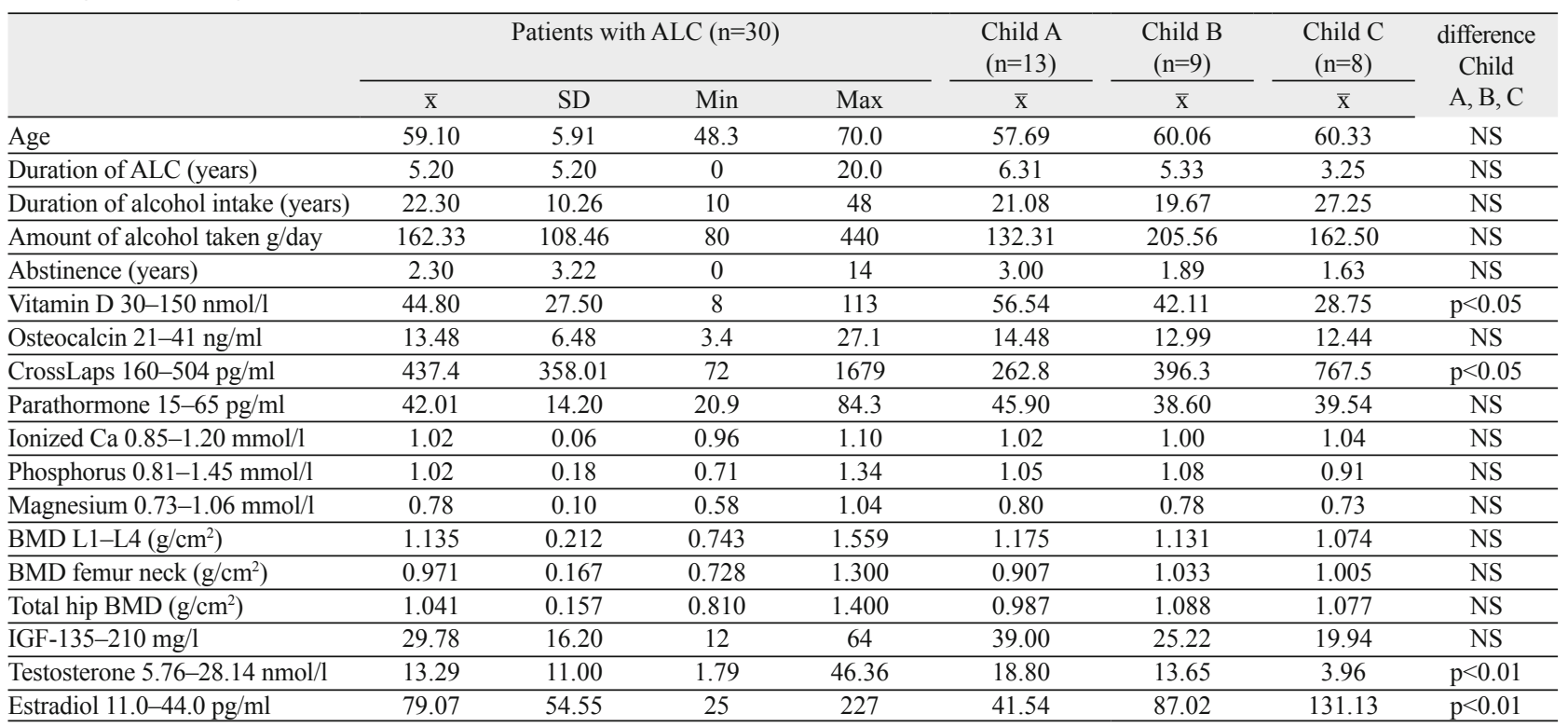

$\mathrm{NS}$ - not significant 


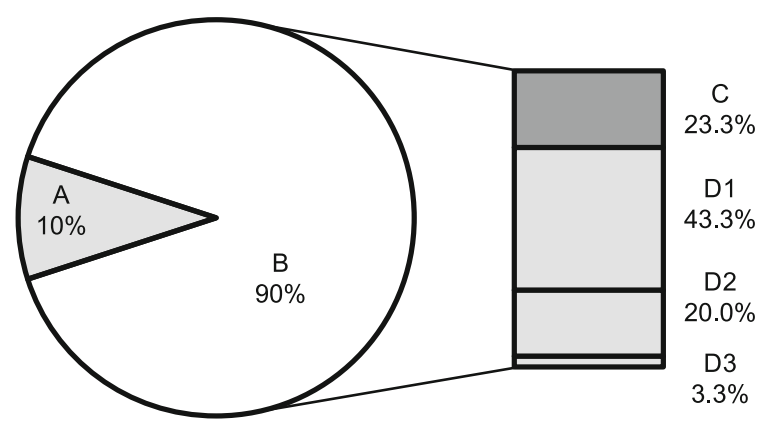

A - adequacy $>80 \mathrm{nmol} / \mathrm{l}(3)$

$\mathrm{B}$ - inadequacy $<80 \mathrm{nmol} / \mathrm{l}(27)$

C - insufficiency $50-79 \mathrm{nmol} / \mathrm{l}(7)$

$\mathrm{D}$ - deficiency $<50 \mathrm{nmol} / \mathrm{l}(20)$

D1 - mild deficiency $25-49 \mathrm{nmol} / \mathrm{l}(13)$

D2 - moderate deficiency $12.5-24 \mathrm{nmol} / \mathrm{l}(6)$

D3 - severe deficiency $<12.5 \mathrm{nmol} / \mathrm{l}(1)$

Fig. 1. Adequacy of vitamin $D$ in only three patients $(10 \%)$, inadequacy in $90 \%(27 / 30)$ patients, while insufficiency and deficiency were observed in $23.33 \%(7 / 30)$ and $66.66 \%(20 / 30)$ patients, respectively. Mild deficiency in $43.33 \%(13 / 30)$ patients, moderate in $20 \%(6 / 30)$ and severe in $3.33 \%(1 / 30)$ patients.

consent was obtained from all patients before they were included in the research.

The following statistical methods have been used in this research: Descriptive statistics: arithmetic mean, standard deviation;
Statistical methods of hypothesis testing: methods comparing metric variables ( t-test) and methods comparing categorical variables ( $\chi^{2}$ test), special, non parametric tests for ordinal variables. Significance level 95\%, with marginal $p$ value $=5 \%(<0.05)$ and $95 \%$ Confidence Interval. Analysis of variance, single-factorial (one-way), nonparametric; Kruskal-Wallis test for evaluating difference significance in medians among three or more independent groups; Mann-Whitney U-test, nonparametric rank-sum test; Pearson correlation coefficient test.

\section{Results}

In patients with ALC, average values of vitamin D were 44.80 $\mathrm{nmol} / 1$, parathormone $42.01 \mathrm{pg} / \mathrm{ml}$, osteokalcin $13.48 \mathrm{ng} / \mathrm{ml}$, Crosslaps $437.4 \mathrm{pg} / \mathrm{ml}$, ionized Ca $1.02 \mathrm{mmol} / 1, \mathrm{Mg} 0.78 \mathrm{mmol} / \mathrm{l}$, phosphorus $1.02 \mathrm{mmol} / 1$.

Patients with Child-Pugh class $\mathrm{C}$ revealed the lowest serum concentration of vitamin D (28.75 nmol/1), highest CrossLaps values $(767.5 \mathrm{pg} / \mathrm{ml})$ and lowest serum-osteocalcin levels (12.44 $\mathrm{ng} / \mathrm{ml})$. Decrease in vitamin D values and osteocalcin level, and increase in CrossLaps value associated with the severity of the disease was apparent (Tab. 1).

Adequacy of vitamin $\mathrm{D}$ was observed in only three patients (10 $\%$ ), inadequacy in $90 \%(27 / 30)$ patients, while insufficiency and deficiency were observed in $23.33 \%$ (7/30) and $66.66 \%$ (20/30) patients, respectively. Mild deficiency was established in 43.33 $\%(13 / 30)$ patients, moderate in $20 \%(6 / 30)$ and severe in $3.33 \%$ (1/30) patients (Fig. 1).

Tab. 2. BMD in the investigated regions in ALC patients with and without osteoporosis and clinical characteristics and laboratory findings in both groups of patients.

\begin{tabular}{|c|c|c|c|c|c|c|c|c|c|c|}
\hline & \multirow{2}{*}{$\begin{array}{c}\begin{array}{c}\text { Patients with } \\
\text { ALC } \\
\mathrm{n}=30(100 \%)\end{array} \\
\frac{\overline{\mathrm{x}}}{}\end{array}$} & \multicolumn{4}{|c|}{$\begin{array}{l}\text { Patients without osteoporosis, } \\
\qquad \mathrm{n}=24(80 \%)\end{array}$} & \multicolumn{4}{|c|}{$\begin{array}{l}\text { Patients with osteoporosis, } \\
\qquad n=6(20 \%)\end{array}$} & \multirow[t]{2}{*}{$\mathrm{p}$} \\
\hline & & $\overline{\mathrm{x}}$ & SD & Min & Max & $\overline{\mathrm{x}}$ & SD & Min & $\operatorname{Max}$ & \\
\hline BMD L1-L4 (g/cm²) & 1.135 & 1.194 & 0.189 & 0.940 & 1.559 & 0.898 & 0.112 & 0.743 & 1.043 & $\mathrm{p}<0.01$ \\
\hline BMD femur neck $\left(\mathrm{g} / \mathrm{cm}^{2}\right)$ & 0.971 & 1.011 & 0.158 & 0.766 & 1.300 & 0.809 & 0.083 & 0.728 & 0.928 & $\mathrm{p}<0.01$ \\
\hline Total hip BMD (g/cm²) & 1.041 & 1.076 & 0.154 & 0.810 & 1.400 & 0.901 & 0.071 & 0.827 & 1.020 & $\mathrm{p}<0.05$ \\
\hline Age & 59.10 & 59.15 & 5.109 & 49.9 & 65.9 & 58.90 & 9.073 & 48.3 & 70.0 & NS \\
\hline Duration of alc. liver cirrhosis & 5.20 & 5.04 & 5.385 & 0 & 20 & 5.83 & 4.73 & 1 & 15 & NS \\
\hline Duration of alcohol intake - years & 22.30 & 21.33 & 10.20 & 10 & 48 & 26.17 & 10.46 & 13 & 44 & NS \\
\hline Amount of alcohol taken g/day & 162.33 & 145.42 & 96.86 & 80 & 440 & 230.0 & 134.9 & 120 & 400 & $\mathrm{p}<0.05$ \\
\hline Vitamin D (30-150 nmol/1) & 44.80 & 48.96 & 29.23 & 8 & 113 & 28.17 & 6.43 & 17 & 34 & NS \\
\hline Osteocalcin $(21-41 \mathrm{ng} / \mathrm{ml})$ & 13.48 & 12.67 & 5.983 & 3.4 & 26.6 & 16.77 & 7.92 & 6.8 & 27.1 & NS \\
\hline CrossLaps (160-504 pg/ml) & 437.4 & 391.3 & 301.6 & 101 & 1679 & 622.0 & 523.2 & 72 & 1467 & NS \\
\hline Parathormone (15-65 pg/ml) & 42.01 & 42.44 & 15.15 & 20.9 & 84.3 & 40.30 & 10.44 & 28.8 & 57.1 & NS \\
\hline Ionized Ca $(0.85-1.20 \mathrm{mmol} / \mathrm{l})$ & 1.02 & 1.02 & 0.06 & 0.90 & 1.11 & 1.00 & 0.03 & 0.96 & 1.02 & NS \\
\hline Magnesium $(0.73-1.06 \mathrm{mmol} / \mathrm{l})$ & 0.78 & 0.77 & 0.19 & 0.6 & 1.04 & 0.86 & 0.16 & 0.76 & 1.04 & NS \\
\hline Phosphorus (0.81-1.45 mmol/l) & 1.02 & 1.03 & 0.19 & 0.71 & 1.34 & 0.99 & 0.16 & 0.72 & 1.14 & NS \\
\hline Bilirubin (mmol/l) & 39.84 & 38.90 & 27.62 & 10 & 93 & 43.62 & 30.53 & 15 & 90 & NS \\
\hline Albumins $(g / 1)$ & 32.12 & 32.92 & 7.56 & 22 & 47 & 29.08 & 6.76 & 20 & 37 & NS \\
\hline IGF-1 (35-210 mg/l) & 29.78 & 29.42 & 15.41 & 13 & 64 & 20.67 & 20.67 & 12 & 64 & NS \\
\hline Testosterone $(5.76-28.14 \mathrm{nmol} / \mathrm{l})$ & 13.29 & 14.95 & 11.48 & 2.10 & 46.36 & 6.68 & 5.55 & 1.79 & 14.37 & NS \\
\hline Estradiol $(11.0-44.0 \mathrm{pg} / \mathrm{ml})$ & 79.07 & 70.18 & 46.69 & 25 & 227 & 114.7 & 73.03 & 30 & 225 & NS \\
\hline FSH $(1.37-13.58 \mathrm{IU} / 1)$ & 5.41 & 5.83 & 4.23 & 0.37 & 18.09 & 3.75 & 2.69 & 0.40 & 7.74 & NS \\
\hline LH (1.14-8.75 IU) & 4.33 & 4.72 & 2.64 & 0.11 & 10.23 & 2.75 & 2.37 & 0.25 & 5.90 & NS \\
\hline
\end{tabular}

NS - not significant 
Increased PTH values were observed in only $7.4 \%(2 / 27)$ of patients with vitamin D inadequacy $\mathrm{D}(<80 \mathrm{nmol} / \mathrm{l})$. One patient had vitamin D level of $75 \mathrm{nmol} / \mathrm{l}$ and PTH $70 \mathrm{pg} / \mathrm{ml}$, whilst another patient revealed vitamin D concentration of $18 \mathrm{nmol} / \mathrm{l}$, and PTH $84.3 \mathrm{pg} / \mathrm{ml}$.

Statistically significant correlations between vitamin $\mathrm{D}$ and following parameters were not determined $(p>0.05)$ : osteocalcin, CrossLaps, $\mathrm{PTH}$, ionized $\mathrm{Ca}$, phosphorus, $\mathrm{Mg}$, bilirubin, INR, IGF-1, AST, ALT, ALP, thrombocyte, BMD L1-L4, BMD hip neck, total hip BMD.

Statistically significant correlations were determined between vitamin $\mathrm{D}$ and total calcium $(\mathrm{p}<0.01)$, vitamin $\mathrm{D}$ and albumin ( $\mathrm{p}$ $<0.01)$, and vitamin D and GGT $(\mathrm{p}<0.05)$.

Out of the total number of 30 patients with ALC, $66.7 \%$ (20/30) of patients had increased estradiol levels. Testosterone values were within the range of reference values in $60.0 \%(18 / 30)$ patients, whereas $26.7 \%(6 / 30)$ patients revealed decreased testosterone levels. In both hormones, highly statistically significant difference was established between patient groups with ChildPugh classes A, B and C ( $\mathrm{p}<0.01)$. Normal levels of FSH (Follicle stimulating hormone) and LH (Luteinizing hormone) were determined in $83.3 \%(25 / 30)$ and $86.7 \%(26 / 30)$ of patients with ALC, respectively. Statistically significant decrease in gonadotropin levels was established that was proportional to the severity of the disease $(p<0.05)$. Average values of FSH, LH, estradiol and testosteron are given in Table 2.

Twenty-one patients (70 \%) had IGF-1 (insulin-like growth factor-1) values below the lower limits of normal. Average value of IGF is given in Table 1.

Of the six patients with osteoporosis, $50 \%(\overline{\mathrm{x}}=61.96$ years $)$ had lowest BMD on femur neck with average BMD $0.738 \mathrm{~g} / \mathrm{cm}^{2}$. Another $50 \%(\bar{x}=55.83$ years $)$ had lowest BMD on L1-L4 region with average BMD $0.836 \mathrm{~g} / \mathrm{cm}^{2}$. Two of all were younger than $50(\overline{\mathrm{x}}=48.6)$ with average Z-score $-2.4\left(\mathrm{BMD} 0.853 \mathrm{~g} / \mathrm{cm}^{2}\right)$ and four patients were older than $50(\overline{\mathrm{x}}=64)$ with average T-score -3.175 (BMD $0.754 \mathrm{~g} / \mathrm{cm}^{2}$ ).

In patients with ALC and osteoporosis average values of ionized $\mathrm{Ca}$ were $1.00 \mathrm{mmol} / \mathrm{l}, \mathrm{Mg} 0.86 \mathrm{mmol} / \mathrm{l}$, phosphorus 0.99 $\mathrm{mmol} / 1$, parathormone $40.30 \mathrm{pg} / \mathrm{ml}$, vitamin D $28.17 \mathrm{nmol} / 1$, osteokalcin $16.77 \mathrm{ng} / \mathrm{ml}$, Crosslaps $622 \mathrm{pg} / \mathrm{ml}$ (Tab. 2).

Average INR in these patients was 1.495 , but in other patients INR was 2.085.

Two patients with osteoporosis were categorized into the Child-Pugh class A, one into class B and three patients into class C.

Statistically significant difference in vitamin D status and serum levels of bone metabolism markers between patients diagnosed with osteoporosis and those without the disease was not established, although the results clearly indicated an increase in CrossLaps and decrease in vitamin D level in patients with osteoporosis.

The only statistically significant difference between patients with and without osteoporosis was established with respect to the amount of daily alcohol intake (145.42 g/day: $230 \mathrm{~g} /$ day), $\mathrm{U}=$ 32.500, $\mathrm{p}<0.05$ (Tab. 2).

\section{Discussion}

Our research revealed a vitamin D inadequacy in $90 \%$ of patients with alcoholic liver cirrhosis. Vitamin D insufficiency and deficiency was established in $23.3 \%$ and $66.7 \%$ of patients, respectively. Patients with Child-Pugh class $\mathrm{C}$ had the lowest serum vitamin D levels. A correlation was established between decreased vitamin D levels and gamma-glutamyl transpeptidase, which is a highly sensitive indicator of hepatobiliary disease, and albumin, which are indicators of liver function impairment.

In patients with vitamin D inadequacy $(<80 \mathrm{nmol} / \mathrm{l})$, elevated PTH values were observed in only $7.4 \%(2 / 27)$ of patients. One patient had vitamin D level of $75 \mathrm{nmol} / \mathrm{l}$ and PTH $70 \mathrm{pg} / \mathrm{ml}$, whilst another patient had vitamin D concentration of $18 \mathrm{nmol} / 1$, and PTH $84.3 \mathrm{pg} / \mathrm{ml}$. Statistically significant correlation between vitamin D and ionized calcium, phosphorus and parathormone levels has not been established. Average serum levels of magnesium and phosphorus were within the reference range, which corresponds with the reports of other authors $(12,13,15,25)$. The condition of normal to low PTH levels in presence of insufficiency or severe deficiency in vitamin D, designated as a "vitamin D-PTH paradox", was described also by other authors. All evidence suggests that multiple mechanisms, other than the vitamin D-PTH axis, might be involved in bone resorption in decreased vitamin $\mathrm{D}$ level $(10,12,13)$.

The obtained results based on the evaluation of bone metabolism markers revealed a decreased bone formation. Osteocalcin level was below the lower limits of normal in $86.7 \%$ of patients. CrossLaps values were within the range of reference values in $66.7 \%$ of patients, whilst increased and decreased levels were observed in $20 \%$ and $13.3 \%$ of patients, respectively. Correlation of vitamin D was observed with neither bone synthesis markers nor bone resorption markers, which was addressed by other authors $(1,22,23)$. It was established that severity of liver cirrhosis correlates with statistically significant increase in marker of bone resorption CrossLaps without impairment of serum parathormone level and no changes in bone mass.

Osteocalcin level is decreased in persons who consume 60-100 $\mathrm{g}$ alcohol per day, which is due to inhibition of proliferation and activation of osteoblasts (10). The average daily alcohol intake in our patients was $162.33 \mathrm{~g} /$ day.

Alcoholic liver disease is characterized by an increase in TNF- $\alpha$ (Tumour necrosis factor alpha) level, a potent pro-inflammatory cytokine that increases bone resorption either directly by osteoclast stimulation or indirectly, via the RANKL - OPG - RANK system. Serum concentrations of TNF receptor I (TNF-R1) correlate with the severity of liver disease. These might be the explanation for significant increase in CrossLaps in our patients with ChildPugh class C. Incidence of osteoporosis observed in these patients did not significantly differ from classes A and B, most probably (though statistically insignificant) because in patients with most severe form of cirrhosis the disease itself had a shorter course as compared with milder forms.

Impaired liver cells produce cytokines that interfere with activation of osteoblasts leading to reduced bone formation. In liver disease, the activated stellate cells produce glycolized isoform of 
plasma fibronectin, so-called oncofetal fibronectin, which negatively correlates with osteocalcin (8).

Chronic inflammation downregulates the 1-alpha hydroxilase by NF- $\kappa \beta$ (nuclear factor-kappa beta) transcription, which may result in inflammation-mediated osteopenia / osteoporosis (20).

TGF- $\beta$ (transforming growth factor- $\beta$ ), a growth factor secreted by osteoblasts, plays a major role in bone metabolism and growth. Vitamin D stimulates the expression of TGF- $\beta$ from human osteoblasts, and also has effects on other growth factors and molecules associated with osteoblasts, namely interleukins (IL1, IL-6), PDGF (platelet degradation growth factor), OPG, and RANKL (22).

Considering a strong immunomodulatory effects of vitamin D, its deficiency may result in increased bone resorption through cytokines: interleukin (IL-2, IL-4, IL-5, IL-12), interferon- $\gamma$ (IFN- $\gamma$ ); independently of PTH (20).

Although the aforementioned has not been addressed in our study, it might theoretically support the facts observed in this research.

In the investigated patients, testosterone levels were within the limits of normal, but statistically significant lower values were obtained in patients with severe form of the disease. The same tendency was established for gonadotropine concentration, whilst estradiol levels progressively increased in parallel with disease severity. Thus, a relatively small number of patients with ALC diagnosed with osteoporosis could partly be explained by high estradiol levels.

IGF-1 values in the investigated patients were below the reference range. Low serum osteocalcin may be directly related with decreased IGF-1 levels in underlying liver cirrhosis $(1,26)$.

Our research revealed the presence of osteoporosis in $20 \%$ (6/30) male patients with ALC. Difference in BMD decrease between patients with different degrees of cirrhosis severity was not statistically significant thus implying the necessity of early evaluation of bone mass. The obtained data are in accordance with the available literature $(1,2,26-28)$.

Our research revealed no statistical significance for vitamin D insufficiency or deficiency related to BMD decrease at neither of measurement sites (lumbar spine, femur neck, total hip). Some authors reported that vitamin D contributed to low BMD in liver cirrhosis, as its deficiency associated with secondary hyperparathyroidism results in bone loss (predominantly cortical bone-hip). These authors consider vitamin $\mathrm{D}$ to be an independent predictor of BMD at cortical bone in patients with liver cirrhosis (12). This was not confirmed in our research. However, it was revealed that the lowest BMD measured in our patients with osteoporosis was that of the femoral neck $\left(\min 0.728 \mathrm{~g} / \mathrm{cm}^{2}\right)$.

With respect to serum levels of bone metabolism markers, no statistical significant difference was established between patients diagnosed with osteoporosis and those without the disease. Evident decrease in osteocalcin level in patients with ALC, as well as increase in CrossLaps serum levels in patients with most severe disease strongly suggest an apparent impairment of bone metabolism in those patients, which could indicate potential loss of bone mass in the future.
Our research revealed that patients diagnosed with osteoporosis consumed higher daily amounts of alcohol than other patients did. Chakkalakal (29) reported that bone loss increases with the prolonged period of alcohol intake or with a higher abusus index. Other authors also pointed out the problem of excessive alcohol consumption as an independent risk factor for osteoporosis associated with 2.8-fold higher risk of hip fracture, as well as significance of inverse relationship between cumulative effects of alcohol intake and BMD. Alcohol decreases the level of vitamin $\mathrm{D}$ by dysregulating enzyme systems of its metabolism $(1,10,11,12,26)$.

Since vitamin K mediates the carboxylation of glutamyl residues in bone protein such as osteocalcin, the vitamin $\mathrm{K}$ deficiency has been considered to be an ancillary factor in the pathogenesis of osteoporosis in liver disease (2).

In patients with ALC and osteoporosis, average INR was 1.495 , but in other patients, INR was 2.085. Despite this, it is known that vitamin $\mathrm{K}$ may also play a role in osteoformation and osteoresorption. The mechanism by which vitamin $\mathrm{K}$ contributes to bone turnover is not clear. (30).

Our study has some limitations, mostly because of low number of patients and no control group included.

\section{Conclusions}

Considerable vitamin D deficiency is apparent in patients with alcoholic liver cirrhosis (ALC), which correlates with the disease severity categorized according to Child-Pugh classification.

Patients with ALC reveal reduced bone formation. In patients with ALC participating in this research, osteoporosis was diagnosed in $20 \%$, with no correlation with disease severity and vitamin D status.

The clinical implication of vitamin D insufficiency/deficiency in patients with ALC is not fully known. Considering the effects of vitamin $\mathrm{D}$ on bone and general health, and connection between its deficiency and severity of the liver disease, it is necessary to periodically determine the vitamin D status in these patients and perform supplementation.

Hence, evaluating the vitamin D status and markers of bone metabolism and bone mass is necessary at the moment of establishing the diagnosis of ALC. Strict abstinence of alcohol intake is necessary for preserving the bone mass. In the view of aforementioned as well as other well-established measures for preserving bone mass, a periodical monitoring of bone metabolism and bone mass is required.

\section{References}

1. Collier J. Bone Disorders in Chronic Liver Disease. Hepatology 2007; 46: 1271-1278.

2. Guanabens N, Pares A. Liver and bone. Archives of Biochemistry and Biophysics 2010; 503: 84-94.

3. WHO. Prevention and management of osteoporosis. Report of a WHO scientific group (WHO, Geneva, 2003). 
573-578

4. WHO Study Group on Assessment of Fracture Risk and its Application to Screening for Postmenopausal Osteoporosis. Assessment of fracture risk and its application to screening for postmenopausal osteoporosis. World Health Organization. Technical report series 843, Geneva, 1994, pp. 1-129.

5. Binkley N, Bilezikian JP, Kendler DL et al. Official positions of the International Society for Clinical Densitometry and Executive Summary of the 2005 Position Development Conference. J Clin Densitom 2006; 9: 4.

6. Čepelak I, Čvorišćec D. Biokemijski biljezi pregradnje kostiju pregled. Biochemia Medica 2009; 19 (1): 17-35.

7. Marcius M, Vrkić N, Getaldić-Švarc B. Analitička procjena komercijalnog teksta za određivanje koncentracije P1NP. Biochem Med 2006; 16 (2): 178-90.

8. Nachbandi I., Van der Merwe S.W. Current understanding of osteoporosis associated with liver disease. Nat Rev Gastroenterol Hepatol 2009; 6: 660-670.

9. DiCecco SR, Francisco-Ziller N. Nutrition in Alcoholic Liver Disease. Nutrit Clin Pract 2006; 21: 245-254.

10. Maurel DB, Boisseau N, Brnhamou CL, Jaffre C. Alcohol and bone: review of dose effects and mechanisms. Osteoporos Int 2012; 23: 1-16.

11. Shankar K, Liu X, Singhal R, Chen JR, Nagarajan S, Badger T, Ronis M. Chronic Ethanol Consumption Leads to Disruption of Vitamin D3 Homeostasis Associated with Induction of Renal 1,25 Dihydroxyvitamin D3-24-Hydroxylase (CYP24A1). Endocrinology 2008; 149 (4): $1748-1756$.

12. Crawford AB, Labio ED, Strasser SI, McCaughan GW. Vitamin D replacement for cirrhosis-related bone disease. Nature reviews Gastroenterology and Hepatology 2006; 3: 689-699.

13. Miroliaee A, Nasiri-Toosi M, Khalilzadeh O, Esteghamati A, Abdollahi A, Mazloumi M. Disturbances of parathyroidhormone-vitamin $\mathrm{D}$ axis in non -cholestatic chronic liver disease: a cross sectional study. Hepatol Int 2010; 4: 634-640.

14. Fisher L, Fisher A. Vitamin D and parathyroid hormone in outpatients with noncholestatic chronic liver disease. Clin Gastroenterol Hepatol 2007; 5: 513-520.

15. Artech J, Narra S, Nair S. Prevalence of vitamin D deficiency in Chronic Liver Disease. Dig Dis Sci 2010; 55: 2624-2628.

16. Dawson-Hughes B, Heaney RP, Holick MF, LIps P, Meunier PJ, Vieth R. Estimates of optimal vitamin D status. Osteoporosis Int 2005; 16: 713-716.
17. Lips P. Vitamin D physiology. Progr Biophys Mol Biol 2006; 92: 4-8.

18. Holick MF. Vitamin D: Evolutionary, Physiological and Health Perspectives. Current Drug Targets 2011; 12: 4-18.

19. Pappa HM, Bern E, Kamin D, Grand R. Vitamin D status in gastrointestinal and liver disease. Curr Opin Gastroenterol 2008; 24: 176-183.

20. Ebert R, Schutze N, Adamski J, Jakob F. Vitamin D signaling is modulated on multiple levels in healt and disease. Mol Cell Endocrinol 2006; 248: 149-159.

21. Brazdilova K, Dlesk A, Koller T, Killinger Z, Payer J. Vitamin D deficiency - a possible link between osteoporosis and metabolic syndrome. Bratisl Med J 2012; 113 (7): 412-416.

22. Driel M, Pols HAP, v Leeuwen. Osteoblast Differentiation and Control by Vitamin D and Vitamin D Metabolites. Curr Pharm Design, 2004; 10: 2535-2555.

23. Diamond T, Stiel D, Mason $\mathbf{R}$ et al. Serum vitamin D metabolites are not responsible for low turnover osteoporosis in chronic liver disease. J Clin Endocrinol Metab 1989; 69: 1234-1239.

24. Puhg RN, Murray-Lyon IM, Dawson JL, Pietroni MC, Williams R. Transection of the oesophagus for bleeding oesophageal varices. Brit J Surg 1973; 60 (8): 646-649.

25. Malham M, Jorgensen SP, Ott P, Agnholt J, Vilstrup H, Borre M, Dahlerup JF. Vitamin D deficiency in cirrhosis relates to liver dysfunction rather than aetiology. World J Gastroenterol 2011; 17 (7): 922-925.

26. Guanabens N, Pares A. Management of osteoporosis in liver disease. Clin Res Hepatol Gastroenterol 2011; 35: 438-445.

27. Collier JD, Ninkovic M, Compston JE. Guidelines on the management of osteoporosis associated with chronic liver disease. GUT 2002; 50 (Suppl I): i1-i9.

28. George J, Ganesh HK, Acharya S, et al. Bone mineral density and disorders of mineral metabolism in chronic liver disease. World J Gastroenterol 2009; 15 (28): 3516-3522.

29. Chakkalakal D. Alcohol-induced Bone Loss and Deficient Bone Repair. Alcohol Clin Exp Res 2005; 29 (12): 2077-2090.

30. Stenova E, Steno B, Killinger Z, Baqi L, Payer J. Effect of long-term oral antikoagulant therapy on bone mineral density and bone turnover markers: a prospective 12 month study. Bratisl Lek Listy 2011; 112 (2): 71-76.

Received March 4, 2013. Accepted February 26, 2014. 